\title{
Conferências Locais de Saúde de Belo Horizonte: dinâmica, efetividade e contribuições para o Plano Municipal de Saúde
}

\author{
Belo Horizonte Local Health Conferences: dynamics, effectiveness \\ and contributions to the Municipal Health Plan
}

Ana Maria Caldeira Oliveira1, Sueli Gandolfi Dallari²

RESUMO O objetivo do estudo é analisar a dinâmica e a efetividade das Conferências Locais de Saúde (CLS), realizadas nas Unidades Básicas de Saúde. O estudo ocorreu durante a XII Conferência Municipal de Saúde em outubro de 2013. Foram utilizadas as técnicas de pesquisa de observação participante e análise documental. Verificou-se que as CLS são realizadas de portas abertas, não existindo um número predeterminado de participantes. Além disso, todos têm direito a voz e voto. O estudo conclui pela efetividade das CLS, pois possibilita a discussão das necessidades de saúde pelos usuários, trabalhadores e gestores na atenção primária, legitimando as decisões políticas, assegurando o direito à saúde.

PALAVRAS-CHAVe Conferências de saúde. Atenção Primária à Saúde. Política de saúde. Democracia.

ABSTRACT The objective of the study is to analyze the dynamics and effectiveness of Local Health Conferences (CLS), which took place in Basic Health Units. The study was conducted at the $12^{a}$ Municipal Health Conference, in October 2013. We used the techniques of participant observation research and document analysis. It was found that the CLS are held open door, without the need of a predetermined number of participants. In addition, everyone is entitled to voice and vote. The study concludes that the CLS are effective, since it allows the discussion of health needs by users, workers and managers in primary health, legitimizing political decisions, and ensuring the right to health.

KEYWORDS Health conferences. Primary Health Care. Health policy. Democracy.

1 Secretaria Municipal 


\section{Introdução}

Na área da saúde, a diretriz constitucional de participação foi regulamentada pela Lei $\mathrm{n}^{0}$ 8.142, de 1990 (BRASIL, 1990), que instituiu os Conselhos e as Conferências de Saúde. Os conselhos são órgãos permanentes que devem atuar na formulação e no controle da execução da política de saúde. Por sua vez, as conferências devem se reunir a cada quatro anos, ordinariamente, em cada esfera de governo, com o objetivo de avaliar a situação de saúde e propor diretrizes para a formulação das políticas de saúde. Dessa forma, a função normativa de debater, decidir e controlar a política pública ressalta a natureza deliberativa dessas instituições (ALMEIDA; CUNHA, 2011).

Assim, as Conferências de Saúde são espaços deliberativos em que os participantes podem influenciar a definição de prioridades nas políticas de saúde (MÜlLER NETO; ARTMANN, 2014). Côrtes (2009) destaca o papel democratizante e de legitimidade que as conferências concedem às decisões ali tomadas. Todavia, Van Stralen et al. (2006) observam que as Conferências de Saúde apresentam restrições à participação direta dos cidadãos, sendo dada ênfase à participação de delegados institucionais. Observam, também, uma ruptura entre as conferências e os conselhos, ou seja, as conferências, não sendo capazes de definir prioridades, produzem relatórios pouco aplicáveis.

A participação social na área da saúde, segundo Bispo Júnior e Martins (2014), não tem sentido unívoco e tampouco atinge resultados iguais. Nesse contexto, a efetividade das instituições participativas tem atraído a atenção dos pesquisadores. Afinal, faz-se necessário conhecer o papel, a capacidade de influir das formas ampliadas de participação na operacionalização da democracia, em função da relação entre participação, deliberação e políticas públicas (AVRITZER, 2011).

O município de Belo Horizonte realizou sua XII Conferência Municipal de Saúde no mês de novembro de 2013. Essa conferência teve como principal objetivo a definição de diretrizes para subsidiar a elaboração do Plano Municipal de Saúde (PMS) 2014-2017. A XII Conferência cumpriu a etapa local, realizando cerca de 147 Conferências Locais de Saúde (CLS) nas Unidades Básicas de Saúde (UBS), e a etapa distrital, com a realização de nove Conferências Distritais de Saúde, referentes aos nove Distritos Sanitários existentes em Belo Horizonte (CMSBH, 2013A).

Nas UBS, funcionam as Comissões Locais de Saúde, espaços públicos institucionalizados do Sistema Único de Saúde (SUS) mais próximos da população. As Comissões Locais de Saúde são responsáveis pela realização das CLS. Para Bispo Júnior e Martins (2012), esses espaços possibilitam o envolvimento e a ampliação da participação da comunidade nas questões locais e gerais de saúde, além de compartilharem o poder. O objetivo do estudo é descrever e analisar a dinâmica do processo conferencista, verificando, também, a efetividade das CLS, visando contribuir para a ampliação da participação da comunidade na Atenção Primária à Saúde (APS), bem como com sua capacidade de influir na tomada de decisão da gestão municipal de saúde.

\section{Metodologia}

Trata-se de estudo empírico descritivo com adoção de metodologia qualitativa. Um estudo de caso único - as CLS - com análise de mais de uma unidade (YIN, 2010). O estudo foi realizado durante a etapa local da XII Conferência Municipal de Saúde, em outubro de 2013. Foram selecionadas sete Comissões Locais de Saúde distribuídas em três Distritos Sanitários. A pesquisa foi autorizada pelo Conselho Municipal de Saúde de Belo Horizonte (CMSBH).

A seleção das Comissões Locais de Saúde, responsáveis pela realização das CLS, foi baseada em três parâmetros: o Índice de 
Vulnerabilidade Social (IVS); maior mobilização social, por regional, na XI Conferência Municipal de Saúde e indicações dos Conselhos Distritais de Saúde sobre Comissões Locais atuantes. O IVS criado pela Secretaria Municipal de Saúde (SMSA) associa indicadores de base populacional, tais como moradia e renda, com indicadores da saúde, como mortalidade infantil, estratificando a população em baixo, médio, elevado e muito elevado risco (SMSA, 2008). As Comissões Locais selecionadas apresentam algumas características semelhantes e outras distintas, retratando um todo complexo (quadro 1).

\begin{tabular}{|c|c|c|c|c|c|}
\hline Data da & Indicação & Comissão & Regional/ & Risco & Mobilização \\
\hline Realização & do & Local de & Distrito & Predominante & Social na XI \\
\hline Conferência & Conselho & Saúde & Sanitário & (IVS) & Conferência \\
\hline Local & Distrital & & & & \\
\hline $15 / 10 / 13$ & $\operatorname{Sim}$ & A & Centro-Sul & Baixo & Fraca \\
\hline 16/10/13 & - & B & Leste & Médio & Média \\
\hline 18/10/13 & & C & Centro-Sul & M. Elevado & Fraca \\
\hline $21 / 10 / 13$ & - & D & Centro-Sul & Elevado & Fraca \\
\hline $22 / 10 / 13$ & - & $\mathrm{E}$ & Norte & Médio & Forte \\
\hline 23/10/13 & - & $\mathrm{F}$ & Norte & Elevado & Forte \\
\hline $24 / 10 / 13$ & Sim & G & Leste & M. Elevado & Média \\
\hline
\end{tabular}

Para a descrição e análise da dinâmica do processo conferencista, foi utilizada a técnica de observação participante com a adoção de um diário de campo. A técnica de pesquisa documental foi utilizada para verificar a efetividade das CLS. Analisaramse os sete Relatórios Finais das CLS acompanhadas, buscando elencar as demandas comuns, e, depois, as demandas prevalentes foram procuradas no Relatório Final da XII Conferência Municipal de Saúde (CMSBH, 2013B). Foram analisados, também, diversos documentos públicos, disponíveis no site do CMSBH, relativos a XII Conferência.

O referencial teórico da pesquisa se apoia em Habermas (1995), para quem a legitimidade das decisões políticas, na perspectiva da democracia deliberativa, decorre de procedimentos em que participam aqueles que serão afetados por estas decisões. Os participantes, em igualdade de condições, expressam e produzem opiniões, sem qualquer tipo de coerção, visando à decisão pelo melhor argumento.

\section{Resultados e discussão}

Com o tema 'Acesso, qualidade e transparência na atenção à saúde em Belo Horizonte', a XII Conferência Municipal de Saúde foi convocada pelo Conselho Municipal de Saúde em parceria com a SMSA (CMSBH, 2013A). De acordo com o regulamento da XII Conferência, as CLS têm como objetivo oferecerem subsídios às Conferências Distritais, e estas, por sua vez, oferecerem subsídios à XII Conferência Municipal. Além disso, as 
CLS devem eleger delegados para participarem das Conferências Distritais, e estas, na sequência, elegem delegados para participarem da XII Conferência Municipal de Saúde (CMSBH, 2013A).

A XII Conferência adotou como insumo para as discussões o documento preparado pela SMSA: 'Monitoramento da execução dos pontos fundamentais e prioritários definidos pela X Conferência Municipal de Saúde de Belo Horizonte' (SMSA, 2013), composto pelas diretrizes deliberadas e pela justificativa para o estado da arte dessas diretrizes e pelo PMS 2010-2013. A proposta da XII Conferência é formular diretrizes para a Política Municipal de Saúde a partir da verificação da realização, ou não, das diretrizes definidas pela X Conferência Municipal e reafirmadas no PMS de 2010-2013.

Ou seja, a política pública cumprindo seu ciclo de formulação/aprovação, implementação, monitoramento e avaliação. Segundo Labra (2009, P. 180), na prática,

o que ocorre é o redesenho da política, seja para modificar os objetivos a fim de adequá-los aos recursos disponíveis ou para mobilizar novos recursos de modo a atingir objetivos pendentes.

Dessa forma, a implementação da política pública desejada só pode ser alcançada mediante um longo processo incremental (LABRA, 2009).

É importante esclarecer que a realização das Conferências de Saúde, em Belo Horizonte, ocorre bienalmente, com a realização de uma Conferência Municipal específica, visando à elaboração do PMS, alternada com a Conferência Municipal, etapa da Conferência Nacional de Saúde (OLIVEIRA; MACHADO; DALLARI, 2012). Assim, foram realizadas a X Conferência e a XII Conferência Municipal de Saúde, visando à elaboração do PMS 2010-2013 e 2014-2017 respectivamente; e a XI Conferência Municipal de Saúde, etapa da XIV Conferência Nacional de Saúde.
Ao visualizar a produção da política como um ciclo, é importante destacar que a proposta de monitoramento da execução das diretrizes definidas pela $\mathrm{X}$ Conferência, substrato do Plano Municipal de Saúde 2010-2013, só foi possível em função de uma mudança no processo conferencista, adotado na realização dessa conferência. Assim, o consenso sobre a necessidade de repensar o formato das Conferências de Saúde (BRASIL, 2013) é colocado em prática na condução da $X$ Conferência Municipal de Saúde.

Realizada no nível local, distrital e municipal, utilizou uma dinâmica processual de priorização ascendente de proposições, a partir de uma matriz comum de Relatório Final, para cada etapa realizada. O produto final, o relatório deliberado pela plenária na Conferência Municipal, exigiu a priorização, pelos delegados, de 'dez pontos fundamentais de realizações e três de não realizações'. Em caso de situações de não consenso, foram realizadas votações (OLIVEIRA; MACHADO; DALLARI, 2012). A adoção desse processo conferencista possibilitou a construção de um Relatório Final objetivo, com priorização de propostas para a Política Municipal de Saúde. Nesse sentido, ao estudarem a realização de Conferências Municipais de Saúde, Müller Neto e Artmann (2014, P. 73) verificaram nos discursos que enfatizam a importância do debate e da deliberação "a sinalização da necessidade da deliberação como um pacto possível de ser alcançado".

\section{Quem participa}

Segundo o regulamento da XII Conferência (CMSBH, 2013A), estão aptas a participarem das CLS as pessoas que comparecem às reuniões das Comissões Locais de Saúde, dos Conselhos Hospitalares e das Unidades de Saúde do SUS/BH, bem como membros da sociedade civil interessados em debater o temário da XII Conferência. Dessa forma, percebe-se que as CLS são realizadas de portas abertas, não existindo um número predeterminado 
de participantes, ou mesmo uma preocupação com o respeito ao critério de paridade. A única exigência é que os participantes sejam vinculados à área de abrangência da UBS, o que é razoável, considerando a organização territorial da APS no SUS.

As CLS revelaram uma forte presença do segmento de trabalhadores da saúde, o que não chega a surpreender, pois as CLS foram realizadas, preferencialmente, nas UBS e em horário de trabalho. O número total de 300 participantes, nas sete CLS analisadas, foi significativo, tendo forte contribuição da CLS E, que registrou 72 participantes. Moroni (2009) chama a atenção para a necessidade de os espaços participativos formularem estratégias claras e eficazes, visando incorporar indivíduos ou grupos sociais alheios à participação (gráfico 1).

Gráfico 1. Participação, por segmento, nas 7 Conferências Locais de Saúde. Belo Horizonte, 2013

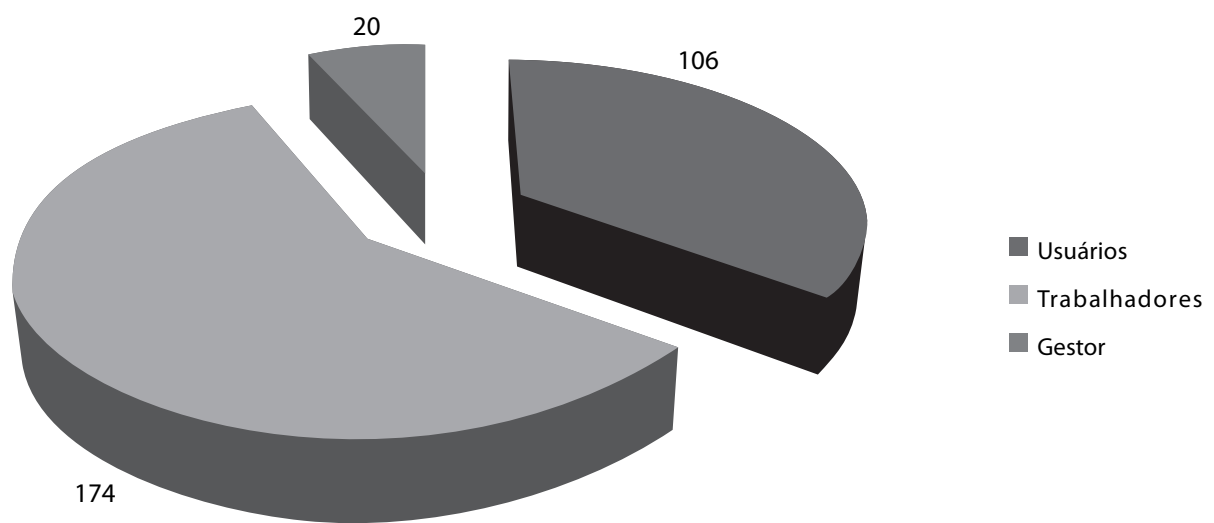

Fizemos propaganda utilizando as ACS. Fizemos propaganda no comércio. A academia da cidade também foi fundamental na divulgação! (DIÁRIO DE CAMPO, 22/10/13).

Dessa maneira, as CLS reproduzem as UBS e se configuram como porta de entrada preferencial da população, para a participação e para os serviços de saúde respectivamente. Todavia, cabe observar que as UBS possuem em média quatro Equipes de Saúde da Família (EqSF), e para o atendimento de uma população classificada com IVS médio, a proporção é de 3.700 pessoas por EqSF (SMSA, 2013), totalizando aproximadamente 14.800 pessoas por território. Isso quer dizer que a participação mais significativa com 72 pessoas é ainda inexpressiva ante a população da respectiva área de abrangência.

Cabe destacar que, por se tratar do primeiro nível de realização do processo conferencista, ainda não existe a figura do delegado, e, dessa forma, todos têm direito a voz e ao voto durante a realização das CLS. Na teoria democrática deliberativa, o princípio da igualdade é associado ao princípio da inclusão deliberativa. O processo conferencista local oferece a todos os participantes as mesmas oportunidades de apresentar propostas, justificar suas razões, participar das discussões e decidir. Essa característica aproxima as CLS da esfera pública vislumbrada por Habermas (1995) em que a sociabilidade horizontal dos cidadãos funcionaria como fonte importante 
para a legitimação discursiva de decisões.

Como citado anteriormente, visando à participação nas Conferências Distritais, as CLS devem eleger delegados com base no critério de paridade. Só pode ser candidato a delegado quem participa das CLS, sendo eleito ou indicado ao final desse evento.

"O que é ser delegado? São aquelas pessoas a quem o poder público delegou a representação" (DIÁRIO DE CAMPO, 16/10/13).

Gurza Lavalle e Isunza Vera (2011) observam que os canais de representação extraparlamentar operam fora do locus por excelência da representação no governo representativo, o Parlamento, e não raro estão vinculados à estrutura administrativa do Poder Executivo. Destinam-se ao desempenho de funções outras que não as legislativas: ora a definição, fiscalização e gestão de políticas públicas. São operados por atores que falam em nome de interesses e segmentos da população.

\section{O processo conferencista}

Ao contrário das Conferências Distritais e da Conferência Municipal, a realização das CLS não é conduzida por um regimento interno próprio. Entretanto, não cabe dizer que a informalidade caracteriza essa etapa. A comissão organizadora da XII Conferência elaborou um roteiro para a realização das CLS, um verdadeiro 'passo a passo', aqui resumidamente apresentado: leitura do documento de Monitoramento; discussão das temáticas apresentadas; elaboração de propostas gerais, sendo necessária a aprovação, no mínimo, por $60 \%$ dos participantes, para serem encaminhadas à Conferência Distrital; não havendo limitação no número de propostas aprovadas, os participantes da CLS deveriam consultar o PMS 2010-2013.

É importante observar a adoção do tradicional critério de aprovação para as propostas - aprovadas, no mínimo, por $60 \%$ dos participantes, para serem encaminhadas à Conferência Distrital, não havendo limitação no número de propostas aprovadas. Isso quer dizer que aquele modelo de processo conferencista, que supera a lógica dos maçantes e longuíssimos relatórios finais, introduzindo a escolha de propostas com priorização, e com validade durante todo o ciclo de produção das políticas de saúde, é posto de lado pela comissão organizadora da XII Conferência.

A comissão organizadora da XII Conferência é composta por membros do CMSBH e dos Conselhos Distritais, comprovando, na prática, a afirmação de Carvalho (1997), que os conselhos e conferências se constituem em um objeto indivisível. Ao descartarem um modelo de processo conferencista vitorioso, proposto e utilizado pela gestão anterior, os conselheiros acabam agindo de maneira semelhante aos políticos. É assim, em um exercício de aproximação, que conselhos de políticas públicas começam a ser tomados como instituições políticas formais (REIS; ARANTES, 2010).

As sete CLS acompanhadas iniciaram os trabalhos com uma breve apresentação abordando a temática da conferência, sendo conduzida pelo gerente, trabalhador da UBS ou por um representante do Conselho Distrital/ Comissão Local. Quatro CLS procederam à leitura do documento de Monitoramento, discussão geral e votação. Três CLS optaram por realizar a leitura do documento de Monitoramento em grupos, divididos pelos eixos temáticos, com posterior discussão geral e votação.

\section{A formulação da política}

Em Belo Horizonte, a SMSA é responsável pela gestão do SUS. O município possui uma população de 2.385.639 habitantes, conta com 147 UBS, 583 EqSF, 307 Equipes de Saúde Bucal (EqSB), 58 Equipes de Saúde Mental (EqSM), 60 Núcleos de Apoio à Saúde da Família (Nasf) e 63 Academias da Cidade (SMSA, 2014).

Conforme proposto na metodologia do 
estudo, foram analisados os sete Relatórios Finais das CLS acompanhadas, sendo aqui apresentadas as demandas prevalentes, por eixo temático.

"A Conferência de Saúde é um espaço para pensar os problemas de saúde de forma global, mas pensando no território" (DIÁRIO DE CAMPO, 24/10/13).

\section{EIXO 1 - GESTÃO DO CUIDADO}

1 - Garantir profissionais para cobertura em período de férias e licença médica para todas as categorias profissionais nas UBS; 2 - Redimensionar o número de EqSB em relação às EqSF. Proporção de 1 EqSF para 1 EqSB; 3 - Garantir uma equipe dos Nasf por UBS.

Uma equipe de Nasf por UBS. Uma Equipe de Saúde Mental por UBS, completa! Uma Equipe de Saúde Bucal para cada equipe de PSF [...] é sonho né!... mas põe aí no papel! (DIÁRIO DE CAMPO, 16/10/13)

Os usuários, trabalhadores da saúde, gestores e membros da sociedade civil interessados em debater o temário da XII Conferência discutiram as reais dificuldades que se interpõem no cotidiano para 'cuidar do cidadão', naquela que é considerada a porta de entrada do sistema de saúde, a atenção primária. Nesse sentido, reivindicaram uma política específica para a reposição de trabalhadores de todas as categorias, profissionais em férias, licenças médicas e aposentadorias, como forma de evitar a sobrecarga de trabalho, assegurando, também, a continuidade da assistência aos usuários.

Ao demandarem por uma melhor relação entre o número de EqSB, EqSF, EqSM e Nasf, as CLS apresentaram um SUS vigoroso, mas, que padece com as dores do crescimento. Retrataram uma atenção primária que se estrutura visando assegurar uma assistência eficaz aos usuários, ainda que esta desejada estruturação possa parecer um 'sonho'. Para
Serapioni e Silva (2011), a qualidade dos serviços prestados à população ainda representa um aspecto crítico, principalmente, quando se considera o número de EqSF atuando sem o profissional médico, atendendo a uma população muito maior que a preconizada pelo Ministério da Saúde, além da elevada rotatividade de profissionais de nível superior.

O documento de Monitoramento da SMSA (2013) esclarece que as contratações provisórias são realizadas mediante a captação e a seleção de profissionais pela Gerência de Gestão do Trabalho. Segundo o documento, não existe limitação para a substituição de profissionais por tempo de afastamento, cabendo à unidade solicitar a contratação do profissional. Entretanto, vale observar a dificuldade para a contração de alguns profissionais, fato explicitado com a edição do Programa Federal Mais Médicos. Segundo a SMSA, em 2008, o SUS/BH possuía 513 EqSF. Atualmente existem 584 EqSF atuando nas 147 UBS com cobertura de 83\% da população. Já as EqSB somavam 195 em 2008, número que, em 2012, passa a ser 307. Dessa maneira, em 2008, havia 1 EqSB para cada 2,66 EqSF, e hoje, a proporção é de 1 EqSB para cada 1,88 EqSF. Existiam, em 2009, 38 Nasf, ou seja, 1 Nasf para cada quatro UBS. Em 2012, 58 Nasf, e, proporcionalmente, 1 Nasf para cada 2,5 UBS.

\section{EIXO 2 - GESTÃO DE REDES}

1 - Ampliar a oferta de exames de apoio diagnóstico, com destaque para a criação de serviço de imagem próprio: serviços de radiologia funcionando dentro do território do distrito; 2 - Garantir acesso às consultas especializadas com redução do tempo de espera; 3 - Melhorar a contrarreferência dos serviços.

O Raio X é baixa complexidade e é realizado fora do território. A distância é muito grande. O usuário não vai porque não tem dinheiro! (DIÁRIO DE CAMPO, 16/10/13). 
As discussões sobre o tema exames de apoio diagnóstico ficaram centradas na radiologia, abordando não só a escassez da oferta, mas também a baixa qualidade da imagem nos exames realizados por prestadores contratados pelo SUS/BH. Segundo os participantes das CLS, essas dificuldades seriam resolvidas com a criação de serviço próprio, localizado na área de abrangência do distrito. Essa exigência é justificada pelo absenteísmo verificado tanto nas consultas para a realização de exames quanto nas consultas especializadas. A necessidade de sistematizar a referência e a contrarreferência é ressaltada nas discussões.

Segundo a SMSA, a capacidade de realização de exames de Raios $X$ foi ampliada na rede própria, com a utilização plena da capacidade física da Unidade de Referência Secundária. Atualmente, cada Distrito Sanitário conta com um Centro de Especialidades Médicas (CEM), e houve ampliação da oferta de consultas especializadas em todos eles. A ampliação da oferta de consultas e exames especializados no Sistema de Regulação (Sisreg) foi de $24 \%$ no período de 2009 a 2013. Houve redução de 14,1\% no tempo de espera para consultas especializadas críticas: angiologia, urologia, neurologia e proctologia, além de algumas especialidades da odontologia: endodontia e disfunção de articulação temporomandibular.

\section{EIXO 3 - GESTÃO DO TRABALHO E DO CONHECIMENTO}

1 - Implantação da Política Municipal de Gestão da Força de Trabalho com realização de concursos públicos; Plano de Cargos, Carreiras e Salários para todos os servidores; 2 - Capacitação permanente para os profissionais de toda a rede SUS/BH, novos e terceiros; 3 - Integração do ensino/serviço - estágios, pesquisas, projetos conjuntos e trocas de experiências no SUS/BH.

Com grande participação de trabalhadores da saúde nas CLS, o eixo Gestão do Trabalho e do Conhecimento foi amplamente debatido. Os trabalhadores reivindicaram a efetivação do Plano de Cargos, Carreiras e Salários; e realização permanente de concursos públicos, como forma de evitar a precarização dos vínculos de trabalho. É importante destacar que parte significativa dos trabalhadores percebem a questão da capacitação permanente como um dos pontos que exigem uma melhor implementação (SERAPIONI; SILVA, 2011), incluindo, também, aqueles que estão em estágio probatório e os terceirizados (porteiros e pessoal da limpeza).

Por sua vez, o documento de Monitoramento apresentou como ações desenvolvidas a realização de concurso público em 2011 para a área da saúde; reajuste salarial em percentuais iguais para todas as categorias da saúde em 2011 e 2012; e o acompanhamento dos treinamentos e capacitações de funcionários nas empresas terceirizadas. Em relação à integração ensino/ serviço, a SMSA reorganizou as parcerias com as instituições de ensino estabelecendo premissas, condições e critérios para celebração de convênios, objetivando reforçar a formação profissional; aderiu ao Pró e PET Saúde - Programas do Ministério da Saúde visando receber alunos das universidades na rede $\mathrm{SUS} / \mathrm{BH}$.

\section{EIXO 4 - GESTÃO E REGIONALIZAC̣ÃO DA SAÚDE}

1 - Aprimorar o sistema de informação. Aumentar o quantitativo de computadores; 2 - Assegurar área física adequada, garantindo recursos para reformas e construções, qualificando as estruturas físicas das UBS; 3 - Melhorar a logística do almoxarifado.

O nosso está uma porcaria. Vocês sabem que não funciona. Quando fala em computador o usuário acha que não interfere, mas interfere! (DIÁRIO DE CAMPO, 18/10/13).

A insatisfação com o sistema de 
informação informatizado é unânime nas CLS. De acordo com os debates, o sistema precisa se adequar às necessidades das diversas atividades exercidas pelos profissionais que atuam nas UBS. O projeto de integração das redes precisa ser concluído. Os participantes reivindicaram o aumento do número de computadores, impressoras e insumos, bem como a melhoria da velocidade da rede. A proposta de qualificação da infraestrutura física e do ambiente de trabalho das UBS é também uma quase unanimidade. Os participantes solicitaram que sejam priorizadas as obras de construções das UBS previstas. Relataram, ainda, que as 'UBS estão cada vez menor para a demanda dos usuários'. A terceira proposta, de melhorar a logística do almoxarifado, está diretamente relacionada com a garantia de insumos para o atendimento adequado dos usuários.

Já o documento de Monitoramento (SMSA, 2013) relatou o aprimoramento do sistema de informação do SUS/BH com a integração de parte de seus sistemas; implantação da referência e contrarreferência no prontuário eletrônico; e o incremento de 1.900 computadores. Apresentou uma lista de obras finalizadas com 13 UBS além da sede do Serviço Médico de Atendimento de Urgência (Samu). Relacionou 27 UBS com obras de reforma e ampliação finalizadas; nove UBS com obras em andamento e mais sete UBS aguardando licitação ou ordem de serviço para a realização das obras. Em relação ao almoxarifado, a SMSA esclareceu que busca, por meio de edital, a contratação de empresa especializada em prestação de serviços de logística.

\section{EIXO 5 - CONTROLE SOCIAL}

1 - Sensibilizar e conscientizar os usuários, trabalhadores da saúde e gestores do SUS quanto à importância de participar; 2 Divulgar e prestar esclarecimentos sobre o controle social para melhor participação; 3 Manter e divulgar a capacitação permanente para o controle social.

"A população ainda não viu grande valor nos conselhos... eles não conhecem também, né!... mas não conhecem porque não vem..." (DIÁRIO DE CAMPO, 16/10/13).

Deveríamos usar a própria Rádio Favela, as igrejas... explicando a importância de estar participando. [...] isso cabe à associação (de moradores), às igrejas, às escolas, às redes, aos parceiros que trabalham com a gente (na UBS). (DIÁRIO DE CAMPO, 18/10/13).

Vários são os relatos de tentativas frustradas de sensibilizar e conscientizar a população sobre a importância de participar no controle social do SUS/BH. Dessa maneira, é extremamente importante conhecer a percepção dos usuários, em relação ao controle social, para identificar os fatores que interferem na participação da comunidade (DAMASCENO; BRITO; MONTEIRO, 2010).

Os participantes chamaram a atenção para o fato de o SUS fazer pouca propaganda, não divulgando o que é feito para a população. Ao contrário, segundo os participantes, a mídia destaca o lado negativo do SUS. Nesse sentido, sugerem que seja realizada uma efetiva divulgação do SUS objetivando trazer mais pessoas para o controle social, 'uma propaganda, quase um marketing!'. Essa sugestão está baseada na ideia de que a comunidade precisa entender o funcionamento do SUS para participar. Propuseram a divulgação das reuniões do Conselho Local nos espaços coletivos, como, por exemplo, igrejas, escolas e creches. Recomendaram a utilização de redes sociais na divulgação do controle social do SUS. Vale ressaltar que o CMSBH utilizou as redes sociais na divulgação das etapas locais, distritais e da própria XII Conferência. A UBS B divulgou os resultados de sua CLS em seu blog.

Outra proposta de grande destaque é a manutenção e divulgação da capacitação permanente para o controle social. Oliveira, 
Ianni e Dallari (2013) já haviam identificado o esforço do CMSBH em realizar cursos de capacitação permanente, as Oficinas de Qualificação para o Controle Social, que têm como mote a expressão 'venha exercer sua cidadania'. Bispo Júnior e Martins (2012) concordam que as capacitações eventuais devem ser substituídas em âmbito municipal por uma Política de Educação Permanente destinada aos profissionais e conselheiros de saúde, com potencial de reflexão e transformação da realidade.

\section{RELATÓRIO FINAL DA XII CONFERÊNCIA MUNICIPAL DE SAÚDE}

O Relatório Final da XII Conferência (CMSBH, 2013B) foi construído por meio de um processo que não se preocupou em priorizar as demandas, contabilizando, assim, 876 propostas. Todas as propostas prevalentes identificadas nos sete Relatórios Finais das CLS acompanhadas foram localizadas nesse Relatório.

\section{Conclusão}

As CLS revelaram-se fóruns fundamentais para orientar, controlar e legitimar a Política Municipal de Saúde, por meio de processos de tomada de decisão descentralizados, realizados na 'ponta' do SUS/BH. Os participantes informados pelas situações-problema experimentadas no cotidiano da APS, na perspectiva dos usuários, trabalhadores da saúde e gestores, tiveram a oportunidade de defender seus pontos de vista, confrontando-os com as diretrizes definidas pela $\mathrm{X}$ Conferência Municipal, com o PMS 20102013, e com as considerações apresentadas pela SMSA, permitindo a transformação argumentativa de opiniões. Nesse sentido, apresentaram suas contribuições para o PMS 2014-2017 por meio dos Relatórios Finais.

Com o intento de conhecer a dinâmica do processo conferencista e a efetividade dessas conferências, este trabalho constatou que existe determinado modelo de processo conferencista que possibilita uma intervenção mais eficaz no ciclo das políticas públicas. Para tanto, observou o processo conferencista com priorização de proposições, representado pela X Conferência Municipal de Saúde; e o processo conferencista tradicional, sem limitação no número de propostas aprovadas, representado pelo processo propriamente dito de realização da XII Conferência Municipal de Saúde.

Verificou-se que a adoção de uma dinâmica processual com priorização ascendente de proposições, a partir de uma matriz comum de Relatório Final, para cada etapa realizada, é mais eficaz do que a elaboração de propostas gerais, aprovadas por $60 \%$ dos participantes, sem limitação no número de propostas aprovadas. A adoção de um processo conferencista com priorização ascendente de proposições possibilita a elaboração de um Relatório Final enxuto e objetivo, com validade durante todo o ciclo de produção das políticas de saúde. Nesse sentido, permite avaliar se o Plano Municipal de Saúde foi elaborado em consonância com as demandas da população, o que se torna mais difícil, quando, por exemplo, tem-se um Relatório Final com 876 propostas, caso da XII Conferência Municipal de Saúde (CMSBH, 2013B).

Além disso, um Relatório Final objetivo pode ser novamente utilizado no fechamento do ciclo das políticas públicas, quatro anos depois, na próxima conferência, como substrato para a verificação da realização, ou não, das diretrizes apontadas nesse Relatório Final. Assim, a partir de resultados concretos, é possível produzir políticas públicas mais efetivas.

Para além da formulação da Política Municipal de Saúde, este estudo demonstrou que as CLS contribuem para o fortalecimento da participação social na APS. Receber a comunidade de portas abertas, dar voz e voto 
a todos os participantes, propiciar a prática de habilidades e procedimentos democráticos, aguçar o sentimento de pertencimento do cidadão à sua comunidade, entre outros, são manifestações da participação tão importantes quanto à produção da política.

Dessa forma, as CLS contribuem também para elevar a qualidade da democracia, pois, ao mesmo tempo que legitimam as decisões políticas, possibilitam o exercício participativo, assegurando o direito à saúde. Nesse contexto, ao analisar a dinâmica do processo conferencista, bem como os produtos deliberados, o estudo conclui pela efetividade das CLS.

\section{Colaboradores}

Ana Maria Caldeira Oliveira trabalhou na concepção, coleta e análise de dados e redação do artigo. Sueli Gandolfi Dallari foi a orientadora, colaborando também na revisão crítica e aprovação da versão a ser publicada.

\section{Referências}

\author{
ALMEIDA, D. C. R.; CUNHA, E. S. M. A análise \\ da deliberação democrática: princípios, conceitos \\ e variáveis relevantes. In: PIRES, R. R. C. (Org.). \\ Efetividade das instituições participativas no Brasil: \\ estratégias de avaliação. Brasília, DF: Ipea, 2011. p. \\ 109-123.
}

AVRITZER, L. A qualidade da democracia e a questão da efetividade da participação: mapeando o debate. In: PIRES, R. R. C. (Org.). Efetividade das instituições participativas no Brasil: estratégias de avaliação. Brasília, DF: Ipea, 2011. p. 13-25.

BISPO JÚNIOR, J. P.; MARTINS, P. C. Envolvimento comunitário na Estratégia de Saúde da Família: dilemas entre institucionalização e efetiva participação. Physis, Rio de Janeiro, v. 22, n. 4, p. 1313-1332, 2012.

Participação social na Estratégia de Saúde da Família: análise da percepção de conselheiros de saúde. Saúde em Debate, Rio de Janeiro, v. 38, n. 102, p. 440451, jul./set. 2014.
BRASIL. Lei $n^{\circ} 8.142$, de 28 de dezembro de 1990. Dispõe sobre a participação da comunidade na gestão do Sistema Único de Saúde (SUS) e sobre as transferências intergovernamentais de recursos financeiros na área da saúde e dá outras providências. Diário Oficial [da] União, Brasília, DF, 1990. Disponível em: <http://www.planalto.gov.br/ccivil_03/LEIS/

L8142.htm>. Acesso em: 23 nov. 2016.

Ministério da Saúde. Novo formato para as conferencias de saúde. Brasília, DF: Ministério da Saúde, 2013. Disponível em: <http://apsredes.org/site2013/ blog/2014/03/14/novo-formato-para-as-conferenciasde-saude/>. Acesso em: 30 mar. 2015.

CARVALHO, A. I. Conselhos de saúde, responsabilidade pública e cidadania: a reforma sanitária como reforma do Estado. In: FLEURY, S. (Org.). Saúde e democracia: a luta do Cebes. Rio de Janeiro: Lemos editorial, 1997. p. 93-111.

CONSELHO MUNICIPAL DE SAÚDE BELO

HORIZONTE (CMSBH). Resolução 345/13: 
Regulamento da XII Conferência Municipal de Saúde de Belo Horizonte. Belo Horizonte: CMSBH, 2013a.

Relatório Final da XII Conferência Municipal de Saúde. Belo Horizonte: CMSBH, 2013b.

CÔRTES S. M. V. Conselhos e conferências de saúde: papel institucional e mudança nas relações entre Estado e sociedade. In: FLEURY, S.; LOBATO, L. V. C. (Org.). Participação, democracia e saúde. Rio de Janeiro: Cebes, 2009. p. 102-128.

DAMASCENO, S. S.; BRITO, G. K. K.; MONTEIRO, C.

H. Fomentando o controle social em rodas de conversa com usuários de uma unidade de saúde da família. Saúde em Debate, Rio de Janeiro, v. 34, n. 84, p. 59-66, jan./mar. 2010.

GURZA LAVALLE, A.; ISUNZA VERA, E. A trama da crítica democrática: da participação à representação $\mathrm{e}$ a accontabillity. Lua Nova, São Paulo, v. 84, p. 353-364, 2011.

HABERMAS, J. Três modelos normativos de democracia. Lua Nova, São Paulo, n. 36, p. 39-54, 1995.

LABRA, M. E. Política Nacional de Participação na Saúde: entre a utopia democrática do controle social e a práxis predatória do clientelismo empresarial. In: FLEURY, S.; LOBATO, L. V. C. (Org.). Participação, democracia e saúde. Rio de Janeiro: Cebes, 2009. p. 176-203.

MORONI, J. A. O Direito à participação no Governo Lula. In: FLEURY, S.; LOBATO, L. V. C. (Org.). Participação, democracia e saúde. Rio de Janeiro: Cebes, 2009. p. 248-269.

\section{MÜLLER NETO, J. S.; ARTMANN, E. Discursos} sobre o papel e a representatividade de conferências municipais de saúde. Cad Saúde Pública, Rio de Janeiro, v. 30, n. 1, p. 68-77, jan. 2014.

OLIVEIRA, A. M. C.; MACHADO, P. C.; DALLARI, S. G. X Conferência Municipal de Saúde Conselheiro Evaristo Garcia: a experiência democrática de Belo Horizonte. Saúde em Debate, Rio de Janeiro, v. 36, n. 92, p. 41-48, jan./mar. 2012.

OLIVEIRA, A. M. C.; IANNI, A. M. Z.; DALLARI, S. G. Controle social no SUS: discurso, ação e reação. Ciênc Saúde Coletiva, Rio de Janeiro, v. 18, n. 8, p. 2329-2338, ago. 2013.

REIS, B. P. W.; ARANTES, R. B. Instituições políticas e controles democráticos: o paradoxal exercício simultâneo do poder e de sua contenção. In: MARTINS, C. B., LESSA, R. (Org.). Horizontes das ciências sociais no Brasil: ciência política. São Paulo: Anpocs, 2010. p. 241-270.

\section{SECRETARIA MUNICIPAL DE SAÚDE DE BELO HORIZONTE (SMSA). Sistema Único de Saúde: relatório de gestão 2007. Belo Horizonte: SMSA, 2008. Disponível em: <http://www.pbh.gov.br/smsa/ arquivos/relatorio_de_gestao_final_24-04-2008.pdf>. Acesso em: 15 jul. 2015.}

Monitoramento da execução dos pontos

fundamentais e prioritários definidos pela $X$ Conferência Municipal de Belo Horizonte. Belo Horizonte: SMSA, 2013.

Sistema Único de Saúde: relatório de gestão 2013.

Belo Horizonte: SMSA, 2014.

SERAPIONI, M.; SILVA, M. G. C. Avaliação

da qualidade do programa Saúde da Família

em municípios do Ceará: uma abordagem

multidimensional. Ciênc Saúde Coletiva, Rio de Janeiro, v. 16, n. 11, p. 4315-4326, nov. 2011.

VAN STRALEN, C. J. et al. Conselhos de saúde: efetividade do controle social em municípios de Goiás e Mato Grosso do Sul. Ciênc Saúde Coletiva, Rio de Janeiro, v. 11, n. 3, p. 621-632, jul./set. 2006.

YIN, R. K. Estudo de caso: planejamento e métodos. 4. ed. Porto Alegre: Bookman, 2010.

\footnotetext{
Recebido para publicação em março de 2016

Versão final em novembro de 2016

Conflito de interesses: inexistente

Suporte financeiro: não houve
} 